\title{
BMJ Open Relationship between gay app use and HIV testing among men who have sex with men in Shenzhen, China: a serial cross-sectional study
}

\author{
Lan Wei, ${ }^{1,2}$ Lin Chen, ${ }^{1}$ Haibo Zhang, ${ }^{1}$ Zhengrong Yang, ${ }^{1}$ Shaochu Liu, ${ }^{1}$ Wei Tan, ${ }^{1}$ \\ Wei Xie, ${ }^{1}$ Liegang Liu, ${ }^{2}$ Jin Zhao, ${ }^{1}$ Jinquan Cheng ${ }^{1}$
}

To cite: Wei L, Chen L, Zhang $\mathrm{H}$, et al. Relationship between gay app use and HIV testing among men who have sex with men in Shenzhen, China: a serial crosssectional study. BMJ Open 2019;9:e028933. doi:10.1136/ bmjopen-2019-028933

- Prepublication history and additional material for this paper are available online. To view these files, please visit the journal online (http://dx.doi. org/10.1136/bmjopen-2019028933).

Received 04 January 2019 Revised 05 July 2019 Accepted 10 July 2019

Check for updates

(C) Author(s) (or their employer(s)) 2019. Re-use permitted under CC BY-NC. No commercial re-use. See rights and permissions. Published by BMJ.

${ }^{1}$ Department of AIDS Control and Prevention, Shenzhen Center for Disease Control and Prevention, Shenzhen, China

${ }^{2}$ Tongji Medical College, Huazhong University of Science and Technology, Wuhan, China

Correspondence to Dr Jinquan Cheng; cjinquan@szcdc.net

\section{ABSTRACT}

Objectives To investigate the relationship between gay app use and HIV testing among men who have sex with men (MSM).

Design Serial cross-sectional study.

Setting A newly well-developed city in China.

Participants 4935 MSM were recruited through offline sampling methods from 2015 to 2017.

Primary and secondary outcomes The primary outcome is the difference in HIV testing between app and non-app users.

Results 2872 (58.2\%) and 2159 (43.7\%) participated MSM had been tested for HIV within lifetime and the past year, respectively. Compared with non-app-using MSM, app-using MSM had a significantly higher prevalence of HIV testing within lifetime (adjusted OR (AOR): $1.48,95 \% \mathrm{Cl}$ 1.27 to 1.72 ) and the past year (AOR: $1.36,95 \% \mathrm{Cl} 1.18$ to 1.57). App-using MSM were more likely to take an HIV test at the Centers for Disease Control and Prevention (AOR: $1.48,95 \% \mathrm{Cl} 1.24$ to 1.76) and community-based organisations (AOR: $1.71,95 \% \mathrm{Cl} 1.44$ to 2.03 ), but less often at gay venues (AOR: $0.49,95 \% \mathrm{Cl} 0.37$ to 0.63 ). Meanwhile, app-using MSM were more likely to take selftesting (AOR: $1.61,95 \% \mathrm{Cl} 1.21$ to 2.14). Predictors of HIV testing in the past year were: having an education level of college or higher (AOR: 1.29, 95\% $\mathrm{Cl} 1.01$ to 1.65), being self-identified as a homosexual (AOR: $1.23,95 \% \mathrm{Cl} 1.02$ to 1.46), being recruited through clinic-based sampling (AOR: $1.30,95 \% \mathrm{Cl} 1.06$ to 1.60), using gay app (AOR: 1.49, $95 \% \mathrm{Cl} 1.21$ to 1.83 ), engaging in group sex (AOR: 1.64, $95 \% \mathrm{Cl} 1.23$ to 2.19 ), having received HIV-related service (AOR: $5.49,95 \% \mathrm{Cl} 4.57$ to 6.60 ), having a high level of HIV-related knowledge (AOR: $1.33,95 \% \mathrm{Cl} 1.10$ to 1.61) and high-risk perception (AOR: $2.95,95 \% \mathrm{Cl} 1.40$ to 6.23 ). Conclusions Gay app use was significantly associated with increased HIV testing among MSM hard to reach by traditional outreach. Therefore, it is imperative to expand HIV testing among non-app-using MSM. Continued efforts, innovative strategies and increased resource are highly needed to realise the first ' 90 ' target.

\section{INTRODUCTION}

HIV testing is an essential component of HIV prevention strategy linked to treatment and care. A lack of knowledge on HIV serostatus

\section{Strengths and limitations of this study}

- This study represents one of the few studies that have compared HIV testing and the preference for testing approaches between app-using men who have sex with men (MSM) and non-app-using MSM in low/middle-income countries, which has a significant implication for future HIV testing expanding strategies.

- Different from most previous online surveys, this study adopted combined offline recruitment methods, providing complementary evidence on this topic.

- A causal relationship was not established because of the cross-sectional study design.

- The findings may not be generalised to the MSM in other areas or settings.

could disable or postpone the initiation of antiviral treatment. Moreover, the HIV screening among asymptomatic HIV carrier may directly reduce HIV transmission, based on the prior findings that those who are unaware of their seropositive status are 3.5 times more likely to transmit HIV than those who know their serostatus. ${ }^{1}$ About $30 \%$ of people living with HIV globally do not know their HIV status. ${ }^{2}$ The first goal of the United Nations' $90-90-90$ targets is that $90 \%$ of all people with HIV will get tested and know their status by 2020 . However, the HIV testing rate in China is far from 90\%. A recent meta-analysis reported that $47 \%$ of men who have sex with men (MSM) have been tested for HIV in China, despite the extensive combined efforts of government, public health agencies and community-based organisations (CBO) in recent years. ${ }^{3}$ Owing to the stigma against homosexuality in China, MSM are less likely to take an HIV test in fear of the exposure of homosexual identity. Furthermore, there are several other barriers to HIV testing, such as 
name-based testing, low perception of risk, long asymptomatic phase and a lack of awareness that testing is free of charge, posing significant challenges to HIV prevention and interventions among MSM in China. ${ }^{4}$ Therefore, developing comprehensive strategies for the promotion of HIV testing among MSM is an urgent priority in China.

In recent years, gay app (geosocial networking application specific to MSM) has reformed significantly the sex-seeking and harm reduction behaviours of MSM. ${ }^{5}$ Studies on the association between gay app use and HIV testing behaviour are limited and inconclusive. Some studies associated app use with increasing HIV testing either within lifetime or in the past year, ${ }^{67}$ whereas others found no difference between app and non-users. ${ }^{8}$ A recent systematic review found that app users are twice likely to test for HIV than non-app users within lifetime. ${ }^{5}$ Another study revealed that social media use was positively associated with HIV testing in Chinese MSM. ${ }^{9}$ Free HIV testing has been available in all provinces of China since 2006. Apart from the health facility-based testing service provided at hospitals/clinics and the Centers for Disease Control and Prevention (CDC), there are also decentralised HIV testing services at peripheral health facilities including CBOs and blood donation sites, and testing service at gay venues and self-testing at home. ${ }^{10}$ As the uptake of HIV testing among MSM is still limited, a better understanding of the testing pattern and preferences among MSM is critical to inform strategies on expanding HIV testing. In addition, few studies exist regarding the impact of app use on the uptake and preference for HIV testing approach among MSM. Therefore, this study aimed to investigate the relationship between app use and HIV testing, and to identify the demographic and behavioural predictors of HIV testing among MSM in Shenzhen, China, where MSM accounted for the largest percentage $(56.7 \%)$ of new infections in recent years.

\section{METHODS}

\section{Source of sample}

From May 2015 to the end of 2017, eligible MSM were recruited through combined offline sampling methods, primarily venue-based method (time location sampling, TLS), and clinic-based methods (respondent-driven sampling, RDS; voluntary counselling and testing (VCT) centre). TLS recruited eligible participants at MSM venues based on a random selection strategy of venue daytime. RDS started with the identification of initial 'seeds' of MSM peers. These seeds were then offered with three coded coupons to recruit new peers, who, in turn, referred those they know and so on. Other participants who visited a VCT centre were also randomly recruited. More information on these methods can be found in the previous study. ${ }^{11}$ The criteria for recruiting were (1) male, Chinese resident, aged 18 years or above; and (2) having had a homosexual contact 6 months prior to the survey in Shenzhen. Meanwhile, the eligibility criteria for male sex worker (also called money boy, MB) participants were: (1) male aged 18 years or older; (2) having lived in Shenzhen for more than 1 month at the time of survey; and (3) having sold sex (oral or anal) to another male in the previous month. Each participant was invited to complete an anonymous questionnaire via a handheld electronic tablet and provide a written informed consent. Then, they were required to take a confidential HIV and syphilis test at Shenzhen Center for Disease Control and Prevention, or a VCT centre.

\section{Behavioural measures}

All data were collected through self-administered questionnaires with information on sociodemographic features, sexual behaviours, gay app use, recreational drug use, HIV testing, HIV-related services, HIV-related knowledge, previous diagnosis of sexually transmitted disease (STD) other than HIV and syphilis infections, source of HIV-related knowledge, HIV and syphilis serostatus and perception of HIV infection. The HIV-related services included distribution of condom, lubricant, peer education, sexually transmitted infection (STI) diagnosis or treatment, HIV counselling or testing, or AIDS/ STI educational materials. A high level of HIV-related knowledge was defined as having correctly answered at least six of the nine questions, otherwise, it was deemed as low to medium level. HIV testing behaviours were evaluated in the following measures: (1) Have you ever taken an HIV test? (2) Have you taken an HIV test in the past year? (3) Where did you receive an HIV test (test at gay venue/hospital/CDC/blood donation site/CBO/at home with self-testing kit)? The main source of HIV-related knowledge was listed as TV, radio, newspaper, books, friends, doctors, consultation service, free promotional materials, bulletin board, internet and school education. The behavioural measures presented in the questionnaire were developed according to the national sentinel surveillance survey for HIV/AIDS and previously verified questionnaires. ${ }^{12}$

\section{HIV and syphilis testing}

HIV and syphilis testing was performed according to the standard procedures established by the laboratory of the Shenzhen Center for Disease Control and Prevention. HIV was tested using a rapid test (Determine HIV-1/2/O; Abbott Laboratories, IL) and ELISA (Wantai Biotech, Beijing, China) for screening, with the positive test confirmed by western blot (Genlabs Diagnostics, Singapore). Syphilis was tested with rapid plasma regain method (Rongsheng Biotech, Shanghai, China) for qualitative screening, with the positive test confirmed by Treponema pallidum particle agglutination assay (Fujirebio, Japan).

\section{Patient and public involvement}

Patients or the public were not involved in the design or planning of the study.

\section{Statistical analysis}

The sociodemographic features and HIV testing-related behaviours were compared between app-using MSM and 
non-app-using MSM, with categorical variables compared using the $\chi^{2}$ test or Fisher's exact test. Univariate and multivariate logistic regressions adjusted for confounders (eg, age, education, marital status, year of survey, and so on) were performed to examine the correlates between app use and testing-related behaviours. To identify the significant predictors of HIV testing within the past year and lifetime, variables with a $p$ value $<0.10$ in the univariate logistic regression models and theoretically important covariates were included for stepwise selection in multivariate regression models. The covariates with a $p$ value $<0.05$ were kept in the final model via manual stepwise selection. Adjusted ORs (AOR) and 95\% CIs were presented. All statistical analyses were performed in $\mathrm{R}$ (V.3.4.3, Foundation for Statistical Computing, Vienna, Austria).

\section{RESULTS}

Among the 4935 participants recruited from 2015 to 2017, a total of 1588 (32.2\%) MSM had used at least one kind of gay app, including 1496 non-commercial MSM (NcMSM) and 92 MBs. The demographic characteristics of all recruited MSM are summarised in table 1. Compared with non-app-using MSM, app-using MSM were younger (28.3 vs 28.8 years), more likely to be unmarried $(92.0 \%$ vs $90.1 \%$ ), having an education level of college or above $(64.0 \%$ vs $42.1 \%)$ and having a monthly income higher than $¥ 7000$ (34.1\% vs $24.3 \%)$. There was no significant difference in ethnicity and duration of residence in Shenzhen between the two groups. There was higher percentage of app-using MSM recruited from clinics (69.6\% vs $41.6 \%)$ and in $2017(56.9 \%$ vs $34.2 \%)$ than that of non-app-using MSM. The prevalence of HIV and syphilis infection was not significantly different between the two groups. However, the prevalence of both HIV and syphilis was significantly higher among non-app-using NcMSM, but not significant for MBs who were less likely to use app and be positive for HIV and syphilis (data not shown).

There were significant differences in testing-related behaviours between app-using and non-app-using MSM in this study (table 2). About $58.2 \%$ and $43.7 \%$ of MSM had been tested for HIV within lifetime and the past year, respectively, in Shenzhen. App-using MSM had significantly higher prevalence of HIV testing within lifetime $(70.2 \%$ vs $52.6 \%)$ and the past year $(52.0 \%$ vs $39.8 \%$ ) than non-app-using MSM. After controlling for age, education, monthly income, marital status, year of sampling, source of sample and type of MSM, MSM who used gay app had significant higher odds of lifetime HIV test (AOR: $1.48,95 \%$ CI 1.27 to 1.72 ) and HIV test in the past year (AOR: $1.36,95 \%$ CI 1.18 to 1.57 ) than those who did not. App-using MSM more commonly know their HIV testing results (AOR: 1.72, 95\% CI 1.16 to 2.54) and their last negative result within the past year (AOR: $1.29,95 \%$ CI 1.09 to 1.53 ). Generally, app-using MSM had higher risk perception of HIV infection than non-app-using MSM (AOR: 1.43, 95\% CI 1.00 to 2.06). For HIV testing approaches, app-using MSM were more likely to have taken an HIV test at a local CDC (AOR: $1.48,95 \% \mathrm{CI} 1.24$ to 1.76 ) or $\mathrm{CBO}$ (AOR: $1.71,95 \% \mathrm{CI}$ 1.44 to 2.03 ) and self-testing (AOR: $1.61,95 \%$ CI 1.21 to 2.14). However, they were less likely to have taken an HIV test at gay venues (AOR: $0.49,95 \%$ CI 0.37 to 0.63 ). There were no significant differences between the two groups for the choices of testing at hospitals and blood donation sites. Moreover, the choices of HIV testing approach by year were compared between the two groups in figure 1 . From 2015 to 2017, the proportion of app-using MSM taking an HIV test at CDC increased, whereas testing at hospitals, CBOs and blood donation sites declined. Notably, there was an increasing rate of self-testing among non-app-using MSM, although the main choices were testing at gay venue, $\mathrm{CDC}$ and $\mathrm{CBO}$. Compared with non-app-using MSM, app-using MSM were more likely to gain HIV-related knowledge from the internet (AOR: 3.07, 95\% CI 2.58 to 3.67 ), books (AOR: 2.04, $95 \%$ CI 1.72 to 2.42 ), doctors (AOR: $1.27,95 \%$ CI 1.00 to 1.61 ), free promotional materials (AOR: $1.76,95 \%$ CI 1.51 to 2.07 ) and bulletin board (AOR: $1.81,95 \%$ CI 1.50 to 2.19), but less likely from TV (AOR: $0.68,95 \%$ CI 0.59 to 0.78 ). For the other source such as radio, newspaper, friends, consultancy service and school education, there was no significant difference between the two groups.

Based on univariate analysis and manual stepwise selection, the final multivariate model was constructed with covariates including year of sampling, source of sample, type of MSM, education level, self-identified sexual identity, sexual role, group sex, app use, HIV-related knowledge and service, previous diagnosis of other STI, risk perception of HIV infection and current HIV and syphilis serostatus (table 3). Multivariate regression results showed the following were factors associated with higher odds of HIV testing in the past year (table 3): having an education level of college or higher (AOR: 1.29, 95\% CI 1.01 to 1.65), being recruited through clinic-based sampling methods (AOR: 1.30, 95\% CI 1.06 to 1.60 ), being self-identified as homosexual (AOR: 1.23, 95\% CI 1.02 to 1.46 ), engaging in group sex (AOR: $1.64,95 \% \mathrm{CI}$ 1.23 to 2.19 ) in the past 6 months, using gay apps (AOR: $1.49,95 \%$ CI 1.21 to 1.83 ), having received offline-based AIDS-related service in the past year (AOR: 5.49 , 95\% CI 4.57 to 6.60 ), having a high level of HIV-related knowledge (AOR: $1.33,95 \%$ CI 1.10 to 1.61 ) and having highrisk perception of HIV infection (AOR: 2.95, 95\% CI 1.40 to 6.23). Meanwhile, MSM who were recruited in 2016 (AOR: 0.54, 95\% CI 0.45 to 0.65) and 2017 (AOR: 0.66, 95\% CI 0.51 to 0.86 ), being MB (AOR: $0.36,95 \%$ CI 0.28 to 0.46$)$, having reported a receptive sexual role during anal sex in the past 6 months (AOR: $0.76,95 \% \mathrm{CI} 0.64$ to 0.90 ) and being HIV seropositive (AOR: $0.66,95 \%$ CI 0.51 to 0.86 ) had significantly lower odds of HIV testing within the past year. We also performed a multivariate analysis to identify the determinants of HIV testing within lifetime, which showed similar results, except for additional 
Table 1 Demographics of app-using and non-app-using MSM

\section{Non-app-using MSM ( $n=3347) \quad$ App-using MSM ( $n=1588)$}

$\mathrm{n}(\%)$

A $(\%) \quad$ P value*

\begin{tabular}{lccc}
\hline Age & $1316(39.3)$ & $461(29.0)$ & $<0.01$ \\
$<25$ & $1618(48.4)$ & $1030(64.9)$ & \\
$25-40$ & $412(12.3)$ & $97(6.1)$ & $<0.05$ \\
$>40$ & $26(23,33)$ & $27(24,31)$ & \\
\hline $\begin{array}{l}\text { Age (median, IQR) } \\
\text { Duration of residence in Shenzhen (year) }\end{array}$ & & 0.299 \\
$<1$ & $802(25.5)$ & $360(24.0)$ & \\
$\geq 1$ & $2342(74.5)$ & $1137(76.0)$ &
\end{tabular}

Ethnicity

$\begin{array}{lccc}\text { Han } & 3237(97.8) & 1524(97.1) & 0.215 \\ \text { Other } & 74(2.2) & 45(2.9) & \end{array}$

Education

\begin{tabular}{|c|c|c|c|}
\hline Junior high school or less & $637(19.0)$ & $146(9.2)$ & $<0.01$ \\
\hline Senior high school & $1301(38.9)$ & 425 (26.8) & \\
\hline College or above & $1409(42.1)$ & $1017(64.0)$ & \\
\hline \multicolumn{4}{|l|}{ Monthly income (¥) } \\
\hline$<3000$ & $196(5.9)$ & $123(7.7)$ & \multirow[t]{3}{*}{$<0.01$} \\
\hline $3000-7000$ & $2337(69.8)$ & $923(58.1)$ & \\
\hline$>7000$ & $814(24.3)$ & $542(34.1)$ & \\
\hline \multicolumn{4}{|l|}{ Marital status } \\
\hline Unmarried & $3015(90.1)$ & $1461(92.0)$ & \multirow[t]{2}{*}{$<0.05$} \\
\hline Married & 332 (9.9) & $127(8.0)$ & \\
\hline \multicolumn{4}{|l|}{ Year of sample } \\
\hline 2015 & $1254(37.5)$ & $118(7.4)$ & \multirow[t]{3}{*}{$<0.01$} \\
\hline 2016 & $949(28.4)$ & $567(35.7)$ & \\
\hline 2017 & $1144(34.2)$ & $903(56.9)$ & \\
\hline \multicolumn{4}{|l|}{ Source of sample } \\
\hline Venue based & $1953(58.4)$ & $483(30.4)$ & \multirow[t]{2}{*}{$<0.01$} \\
\hline Clinic based & $1394(41.6)$ & $1105(69.6)$ & \\
\hline \multicolumn{4}{|l|}{ Type of MSM } \\
\hline NcMSM & 2117 (63.3) & $1496(94.2)$ & \multirow[t]{2}{*}{$<0.01$} \\
\hline MB & $1230(36.7)$ & $92(5.8)$ & \\
\hline \multicolumn{4}{|l|}{ HIV } \\
\hline Negative & 3005 (89.8) & $1414(89.0)$ & \multirow[t]{2}{*}{0.458} \\
\hline Positive & $342(10.2)$ & $174(11.0)$ & \\
\hline \multicolumn{4}{|l|}{ Syphilis } \\
\hline Negative & $2983(89.1)$ & 1419 (89.4) & \multirow[t]{2}{*}{0.844} \\
\hline Positive & $364(10.9)$ & $169(10.6)$ & \\
\hline \multicolumn{4}{|c|}{ Previous diagnosis of other STDs } \\
\hline No & 3119 (93.2) & $1430(90.1)$ & \multirow[t]{2}{*}{$<0.01$} \\
\hline Yes & $228(6.8)$ & $158(9.9)$ & \\
\hline
\end{tabular}

${ }^{*}$ All P values in this column were derived from the comparison between non-app-using MSM and app-using MSM. MB, money boy (male sex worker); MSM, men who have sex with men; NcMSM, non-commercial MSM; STD, sexually transmitted disease. 
Table 2 HIV testing-related behaviours between app-using and non-app-using MSM

\begin{tabular}{|c|c|c|c|c|}
\hline All & $\begin{array}{l}\text { Non-app-using MSM } \\
(\mathrm{n}=3347) \mathrm{n}(\%)\end{array}$ & $\begin{array}{l}\text { App-using MSM } \\
(n=1588) n(\%)\end{array}$ & OR $(95 \% \mathrm{Cl})$ & AOR $(95 \% \mathrm{Cl})$ \\
\hline \multicolumn{5}{|l|}{ Ever tested for HIV } \\
\hline No & $1587(47.4)$ & $474(29.8)$ & 1 & 1 \\
\hline Yes & $1758(52.6)$ & $1114(70.2)$ & $2.12(1.87 \text { to } 2.41)^{\star \star}$ & $1.48(1.27 \text { to } 1.72)^{\star \star}$ \\
\hline \multicolumn{5}{|l|}{ HIV test in the past year } \\
\hline 0 & $2014(60.2)$ & $762(48.0)$ & 1 & 1 \\
\hline 1 & $1333(39.8)$ & $826(52.0)$ & $1.64(1.45 \text { to } 1.85)^{\star \star}$ & $1.36(1.18 \text { to } 1.57)^{\star \star}$ \\
\hline \multicolumn{5}{|c|}{ Did you know your testing results? } \\
\hline Not every time & $125(7.1)$ & $42(3.8)$ & 1 & 1 \\
\hline Yes & 1635 (92.9) & 1072 (96.2) & $1.95(1.36 \text { to } 2.79)^{\star *}$ & $1.72(1.16 \text { to } 2.54)^{\star *}$ \\
\hline \multicolumn{5}{|l|}{ Last HIV negative result } \\
\hline Over 1 year ago & $922(53.0)$ & $529(47.9)$ & 1 & 1 \\
\hline Within the past year & $818(47.0)$ & $576(52.1)$ & $1.23(1.06 \text { to } 1.43)^{\star \star}$ & $1.29(1.09 \text { to } 1.53)^{\star \star}$ \\
\hline \multicolumn{5}{|c|}{ Perception of being infected by HIV } \\
\hline No or little chance & $3263(97.5)$ & $1513(95.3)$ & 1 & 1 \\
\hline Rather big chance & $84(2.5)$ & $75(4.7)$ & $1.93(1.40 \text { to } 2.64)^{\star \star}$ & $1.43(1.00 \text { to } 2.06)^{*}$ \\
\hline \multicolumn{5}{|c|}{ Where did you receive HIV testing? Gay venue } \\
\hline No & $1203(68.4)$ & $977(87.7)$ & 1 & 1 \\
\hline Yes & $557(31.6)$ & $137(12.3)$ & $0.30(0.25 \text { to } 0.37)^{\star \star}$ & $0.49(0.37 \text { to } 0.63)^{\star \star}$ \\
\hline \multicolumn{5}{|c|}{ Where did you receive HIV testing? Hospital } \\
\hline No & $1434(81.5)$ & $832(74.7)$ & 1 & 1 \\
\hline Yes & $326(18.5)$ & $282(25.3)$ & $1.49(1.24 \text { to } 1.78)^{\star \star}$ & $1.18(0.96$ to 1.44$)$ \\
\hline \multicolumn{5}{|c|}{ Where did you receive HIV testing? CDC } \\
\hline No & $1233(70.1)$ & $637(57.2)$ & 1 & 1 \\
\hline Yes & $527(29.9)$ & $477(42.8)$ & $1.75(1.50 \text { to } 2.05)^{\star \star}$ & $1.48(1.24 \text { to } 1.76)^{\star \star}$ \\
\hline \multicolumn{5}{|c|}{ Where did you receive HIV testing? Blood donation site } \\
\hline No & $1719(97.7)$ & $1093(98.1)$ & 1 & 1 \\
\hline Yes & $41(2.3)$ & $21(1.9)$ & $0.81(0.47$ to 1.37$)$ & 0.91 (0.51 to 1.64$)$ \\
\hline \multicolumn{5}{|c|}{ Where did you receive HIV testing? CBO } \\
\hline No & $1141(64.8)$ & $610(54.8)$ & 1 & 1 \\
\hline Yes & $619(35.2)$ & $504(45.2)$ & $1.52(1.31 \text { to } 1.78)^{\star \star}$ & $1.71(1.44 \text { to } 2.03)^{\star \star}$ \\
\hline \multicolumn{5}{|c|}{ Where did you receive HIV testing? Self-testing } \\
\hline No & $1657(94.1)$ & $956(85.8)$ & 1 & 1 \\
\hline Yes & $103(5.9)$ & $158(14.2)$ & $2.66(2.05 \text { to } 3.45)^{\star \star}$ & $1.61(1.21 \text { to } 2.14)^{* \star}$ \\
\hline
\end{tabular}

The main source to gain HIV-related knowledge: TV

\begin{tabular}{|c|c|c|c|c|}
\hline No & $1805(54.5)$ & 1077 (68.6) & 1 & 1 \\
\hline Yes & $1504(45.5)$ & $492(31.4)$ & $0.55(0.48 \text { to } 0.62)^{\star \star}$ & $0.68(0.59 \text { to } 0.78)^{\star \star}$ \\
\hline \multicolumn{5}{|c|}{ The main source to gain HIV-related knowledge: radio } \\
\hline No & $3028(91.5)$ & $1435(91.5)$ & 1 & 1 \\
\hline Yes & $281(8.5)$ & $134(8.5)$ & 1.01 (0.81 to 1.25$)$ & $0.93(0.73$ to 1.19$)$ \\
\hline
\end{tabular}

The main source to gain HIV-related knowledge: newspaper

\begin{tabular}{ccccc} 
No & $2757(83.3)$ & $1278(81.5)$ & 1 & 1 \\
Yes & $552(16.7)$ & $291(18.5)$ & $1.14(0.97$ to 1.33$)$ & $1.10(0.92$ to 1.31$)$ \\
The main source to gain HIV-related knowledge: books & $1135(72.3)$ & 1 & 1 \\
\hline No & $2788(84.3)$ & & \\
\hline
\end{tabular}


Table 2 Continued

\begin{tabular}{|c|c|c|c|c|}
\hline All & $\begin{array}{l}\text { Non-app-using MSM } \\
(\mathrm{n}=3347) \mathrm{n}(\%)\end{array}$ & $\begin{array}{l}\text { App-using MSM } \\
(n=1588) n(\%)\end{array}$ & OR $(95 \% \mathrm{Cl})$ & AOR $(95 \% \mathrm{Cl})$ \\
\hline Yes & $521(15.7)$ & $434(27.7)$ & $2.05(1.77 \text { to } 2.37)^{\star \star}$ & $2.04(1.72 \text { to } 2.42)^{\star \star}$ \\
\hline \multicolumn{5}{|c|}{ The main source to gain HIV-related knowledge: friends } \\
\hline No & $2764(83.5)$ & $1257(80.1)$ & 1 & 1 \\
\hline Yes & $545(16.5)$ & $312(19.9)$ & $1.26(1.08 \text { to } 1.47)^{\star \star}$ & $0.92(0.77$ to 1.09$)$ \\
\hline \multicolumn{5}{|c|}{ The main source to gain HIV-related knowledge: doctors } \\
\hline No & $3016(91.1)$ & 1405 (89.5) & 1 & 1 \\
\hline Yes & $293(8.9)$ & $164(10.5)$ & $1.20(0.98$ to 1.47$)$ & $1.27(1.00 \text { to } 1.61)^{\star}$ \\
\hline \multicolumn{5}{|c|}{ The main source to gain HIV-related knowledge: consultation service } \\
\hline No & $3125(94.4)$ & $1476(94.1)$ & 1 & 1 \\
\hline Yes & $184(5.6)$ & $93(5.9)$ & 1.07 (0.83 to 1.38$)$ & $0.80(0.60$ to 1.07$)$ \\
\hline \multicolumn{5}{|c|}{ The main source to gain HIV-related knowledge: free promotional materials } \\
\hline No & $2508(75.8)$ & $1069(68.1)$ & 1 & 1 \\
\hline Yes & $801(24.2)$ & 500 (31.9) & $1.46(1.28 \text { to } 1.67)^{\star \star}$ & $1.76(1.51 \text { to } 2.07)^{\star \star}$ \\
\hline
\end{tabular}

The main source to gain HIV-related knowledge: bulletin board

\begin{tabular}{|c|c|c|c|c|}
\hline No & $2960(89.5)$ & $1235(78.7)$ & 1 & 1 \\
\hline Yes & $349(10.5)$ & $334(21.3)$ & $2.29(1.95 \text { to } 2.70)^{\star \star}$ & $1.81(1.50 \text { to } 2.19)^{\star *}$ \\
\hline \multicolumn{5}{|c|}{ The main source to gain HIV-related knowledge: internet } \\
\hline No & $1370(41.4)$ & $226(14.4)$ & 1 & 1 \\
\hline Yes & $1939(58.6)$ & $1343(85.6)$ & $4.20(3.59 \text { to } 4.91)^{\star \star}$ & $3.07(2.58 \text { to } 3.67)^{\star \star}$ \\
\hline
\end{tabular}

The main source to gain HIV-related knowledge: school education

\begin{tabular}{lcccl} 
No & $3137(94.8)$ & $1408(89.7)$ & 1 & 1 \\
Yes & $172(5.2)$ & $161(10.3)$ & $2.09(1.67 \text { to } 2.61)^{\star \star}$ & $0.98(0.76$ to 1.26$)$ \\
\hline
\end{tabular}

“*”, $\mathrm{p}<0.05$; “**”, $\mathrm{p}<0.01$; OR, Odds ratio; AOR, adjusted odds ratio after controlling for age, education, monthly income, marital status, year of sample, source of sample, and type of MSM. CDC, center for disease control and prevention; CBO, community based organization. $\mathrm{CBO}$, community-based organisation; CDC, Centers for Disease Control and Prevention; MSM, men who have sex with men.

predictors, such as older age, multiple sexual partners, previous diagnosis of other STD and gaining HIV-related knowledge mainly from consultation services (see the online supplementary table).

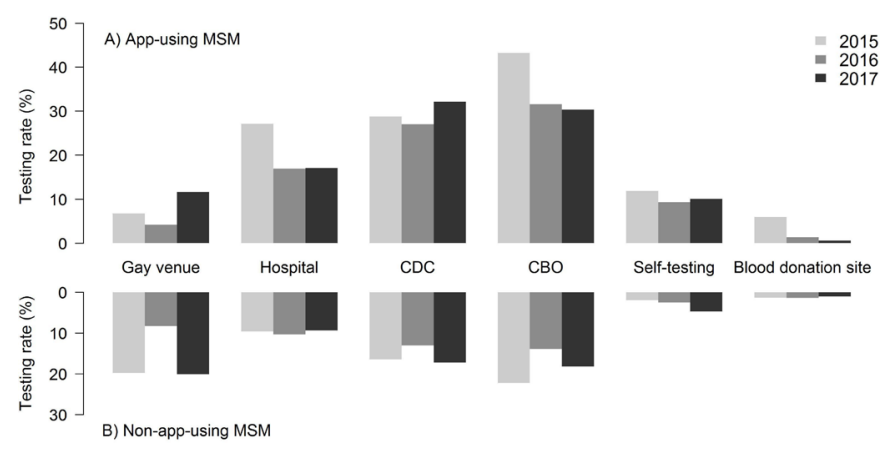

Figure 1 HIV testing approaches of app-using and nonapp-using MSM in Shenzhen, China, 2015-2017. CBO, community-based organisation; CDC, Centers for Disease Control and Prevention; MSM, men who have sex with men.

\section{DISCUSSION}

The HIV testing rates within lifetime and the past year were significantly higher among app-using than non-appusing MSM. Particularly, app-using MSM were more likely to take an HIV test at CDC and CBO, and a self-testing than non-app-using MSM, but less likely to take a test at gay venues. Gay app use was significantly associated with higher odds of lifetime HIV testing. As there were few studies that addressed the difference in choices of HIV testing approaches between app-using and non-app-using MSM, this study has significant implication for future HIV testing expanding strategies.

Our result showed that the prevalence of lifetime HIV testing among MSM in Shenzhen $(58.2 \%)$ was comparable to that reported in other areas $(60.3 \%-63.1 \%)$ in China. ${ }^{13}{ }^{14}$ Specifically, app-using MSM had a relatively higher prevalence of lifetime HIV testing than non-appusing MSM ( $70.2 \%$ vs $52.6 \%$ ), which is similar to an online study from China $(69.7 \%$ vs $55.5 \%){ }^{7}$ The prevalence of lifetime testing among app-using MSM in this study was, however, lower than that in online studies from the USA $(83.2 \%-90 \%) .{ }^{6}{ }^{15}$ Previous research has demonstrated that some gay apps were used to link MSM to HIV testing 
Table 3 Factors associated with HIV testing in the past year among MSM

\begin{tabular}{|c|c|c|c|c|}
\hline Variables & $\begin{array}{l}\text { Not tested } \\
(\mathrm{n}=2776) \mathrm{n}(\%)\end{array}$ & $\begin{array}{l}\text { Tested }(\mathrm{n}=2159) \\
\mathrm{n}(\%)\end{array}$ & OR $(95 \% \mathrm{Cl})$ & AOR $(95 \% \mathrm{Cl})$ \\
\hline \multicolumn{5}{|l|}{ Age } \\
\hline$<25$ & $1153(64.9)$ & $624(35.1)$ & 1 & \\
\hline $25-40$ & $1131(51.0)$ & $1086(49.0)$ & $1.77(1.56 \text { to } 2.01)^{\star \star}$ & - \\
\hline$>40$ & $491(52.2)$ & $449(47.8)$ & $1.69(1.44 \text { to } 1.99)^{\star \star}$ & - \\
\hline \multicolumn{5}{|l|}{ Residence in Shenzhen (year) } \\
\hline$<1$ & $674(58.0)$ & $488(42.0)$ & 1 & - \\
\hline$\geq 1$ & $1928(55.4)$ & $1551(44.6)$ & 1.11 (0.97 to 1.27$)$ & - \\
\hline \multicolumn{5}{|l|}{ Ethnicity } \\
\hline Han & $2659(55.8)$ & $2102(44.2)$ & 1 & - \\
\hline Other & $62(52.1)$ & $57(47.9)$ & 1.16 (0.81 to 1.67$)$ & - \\
\hline \multicolumn{5}{|l|}{ Education } \\
\hline Junior high school or less & $491(62.7)$ & 292 (37.3) & 1 & 1 \\
\hline Senior high school & $1103(63.9)$ & $623(36.1)$ & 0.95 (0.80 to 1.13$)$ & $0.90(0.70$ to 1.15$)$ \\
\hline College or above & $1182(48.7)$ & $1244(51.3)$ & $1.77(1.50 \text { to } 2.09)^{\star \star}$ & $1.29(1.01 \text { to } 1.65)^{*}$ \\
\hline \multicolumn{5}{|l|}{ Monthly income ( $¥)$} \\
\hline$<3000$ & $192(60.2)$ & $127(39.8)$ & 1 & \\
\hline $3000-7000$ & $1941(59.5)$ & $1319(40.5)$ & $1.03(0.81$ to 1.30$)$ & - \\
\hline$>7000$ & $643(47.4)$ & $713(52.6)$ & $1.68(1.31 \text { to } 2.15)^{\star \star}$ & - \\
\hline \multicolumn{5}{|l|}{ Marital status } \\
\hline Single & $2540(56.7)$ & $1936(43.3)$ & 1 & - \\
\hline Married & $236(51.4)$ & $223(48.6)$ & $1.24(1.02 \text { to } 1.50)^{\star}$ & - \\
\hline \multicolumn{5}{|l|}{ Year of sample } \\
\hline 2015 & $757(55.2)$ & $615(44.8)$ & 1 & 1 \\
\hline 2016 & $972(64.1)$ & $544(35.9)$ & $0.69(0.59 \text { to } 0.80)^{\star \star}$ & $0.54(0.45 \text { to } 0.65)^{\star \star}$ \\
\hline 2017 & $1047(51.1)$ & $1000(48.9)$ & $1.18(1.03 \text { to } 1.35)^{\star}$ & $0.65(0.48 \text { to } 0.88)^{\star \star}$ \\
\hline \multicolumn{5}{|l|}{ Type of MSM } \\
\hline NcMSM & $1501(61.6)$ & $935(38.4)$ & 1 & \\
\hline MB & $1275(51.0)$ & $1224(49.0)$ & $1.54(1.38 \text { to } 1.73)^{\star \star}$ & $0.36(0.28 \text { to } 0.46)^{\star \star}$ \\
\hline \multicolumn{5}{|l|}{ Source of sample } \\
\hline Venue based & $1839(50.9)$ & $1774(49.1)$ & 1 & 1 \\
\hline Clinic based & 937 (70.9) & $385(29.1)$ & $0.43(0.37 \text { to } 0.49)^{* *}$ & $1.30(1.06 \text { to } 1.60)^{\star}$ \\
\hline \multicolumn{5}{|c|}{ Self-identified as a homosexual } \\
\hline No & $777(58.7)$ & $546(41.3)$ & 1 & 1 \\
\hline Yes & 1999 (55.3) & $1613(44.7)$ & $1.15(1.01 \text { to } 1.30)^{\star}$ & $1.23(1.02 \text { to } 1.46)^{\star}$ \\
\hline \multicolumn{5}{|l|}{ Receptive sexual role } \\
\hline No & $1764(54.2)$ & $1490(45.8)$ & 1 & 1 \\
\hline Yes & $1012(60.2)$ & $668(39.8)$ & $0.78(0.69 \text { to } 0.88)^{\star *}$ & $0.76(0.64 \text { to } 0.90)^{\star \star}$ \\
\hline \multicolumn{5}{|l|}{ In a relationship } \\
\hline No & $275(50.4)$ & $271(49.6)$ & 1 & - \\
\hline Yes & $451(46.9)$ & $510(53.1)$ & 1.15 (0.93 to 1.42$)$ & - \\
\hline \multicolumn{5}{|c|}{ Sexual partners in the past 6 months, $n$} \\
\hline 0 & $881(63.9)$ & $498(36.1)$ & 1 & \\
\hline $1-5$ & $1462(49.5)$ & $1491(50.5)$ & $1.8(1.58 \text { to } 2.06)^{\star \star}$ & - \\
\hline$>5$ & 433 (71.9) & $169(28.1)$ & $0.69(0.56 \text { to } 0.85)^{\star \star}$ & - \\
\hline
\end{tabular}


Table 3 Continued

\begin{tabular}{|c|c|c|c|c|}
\hline Variables & $\begin{array}{l}\text { Not tested } \\
(n=2776) n(\%)\end{array}$ & $\begin{array}{l}\text { Tested }(n=2159) \\
n(\%)\end{array}$ & OR $(95 \% \mathrm{Cl})$ & AOR $(95 \% \mathrm{Cl})$ \\
\hline \multicolumn{5}{|c|}{ Engaged in ONS in the past 6 months } \\
\hline Yes & $918(56.1)$ & $717(43.9)$ & $1.25(1.08 \text { to } 1.44)^{\star \star}$ & - \\
\hline \multicolumn{5}{|c|}{ Engaged in group sex in the past 6 months } \\
\hline \multicolumn{5}{|c|}{ Engaged in commercial service in the past 6 months } \\
\hline No & $1736(59.0)$ & $1207(41.0)$ & 1 & - \\
\hline Yes & $105(53.8)$ & $90(46.2)$ & $1.23(0.92$ to 1.65$)$ & - \\
\hline \multicolumn{5}{|c|}{ Condom use of anal sex in the past 6 months } \\
\hline No & $66(54.1)$ & $56(45.9)$ & 1 & - \\
\hline Yes & $998(51.5)$ & $941(48.5)$ & $1.11(0.77$ to 1.60$)$ & - \\
\hline \multicolumn{5}{|c|}{ Received offline-based HIV-related service in the past year } \\
\hline No & $1367(77.0)$ & $408(23.0)$ & 1 & 1 \\
\hline Yes & 1409 (44.6) & $1751(55.4)$ & $4.16(3.65 \text { to } 4.75)^{\star \star}$ & $5.49(4.57 \text { to } 6.60)^{\star *}$ \\
\hline \multicolumn{5}{|l|}{ Gay app use } \\
\hline No & $2014(60.2)$ & $1333(39.8)$ & 1 & 1 \\
\hline Yes & $762(48.0)$ & $826(52.0)$ & $1.64(1.45 \text { to } 1.85)^{\star \star}$ & $1.49(1.21 \text { to } 1.83)^{\star *}$ \\
\hline \multicolumn{5}{|l|}{ HIV serostatus } \\
\hline Negative & $2461(55.7)$ & 1958 (44.3) & 1 & \\
\hline Positive & $315(61.0)$ & $201(39.0)$ & $0.80(0.67 \text { to } 0.97)^{\star}$ & $0.66(0.51 \text { to } 0.86)^{\star \star}$ \\
\hline \multicolumn{5}{|l|}{ Syphilis serostatus } \\
\hline Negative & $2489(56.5)$ & $1913(43.5)$ & 1 & - \\
\hline Positive & $287(53.8)$ & $246(46.2)$ & $1.12(0.93$ to 1.34$)$ & - \\
\hline \multicolumn{5}{|c|}{ Perception of HIV infection } \\
\hline No or little chance & $2744(56.4)$ & $2118(43.6)$ & 1 & 1 \\
\hline Rather big chance & $32(43.8)$ & $41(56.2)$ & $1.66(1.04 \text { to } 2.65)^{\star}$ & $2.95(1.40 \text { to } 6.23)^{\star \star}$ \\
\hline \multicolumn{5}{|c|}{ The main source to gain HIV-related knowledge: TV } \\
\hline No & $1640(56.9)$ & $1242(43.1)$ & 1 & - \\
\hline Yes & $1080(54.1)$ & $916(45.9)$ & $1.12(1.00$ to 1.26$)$ & - \\
\hline \multicolumn{5}{|c|}{ The main source to gain HIV-related knowledge: radio } \\
\hline No & 2508 (56.2) & 1955 (43.8) & 1 & - \\
\hline Yes & $212(51.1)$ & $203(48.9)$ & $1.23(1.00 \text { to } 1.50)^{\star}$ & - \\
\hline \multicolumn{5}{|c|}{ The main source to gain HIV-related knowledge: newspaper } \\
\hline No & $2247(55.7)$ & $1788(44.3)$ & 1 & - \\
\hline
\end{tabular}

Continued 
Table 3 Continued

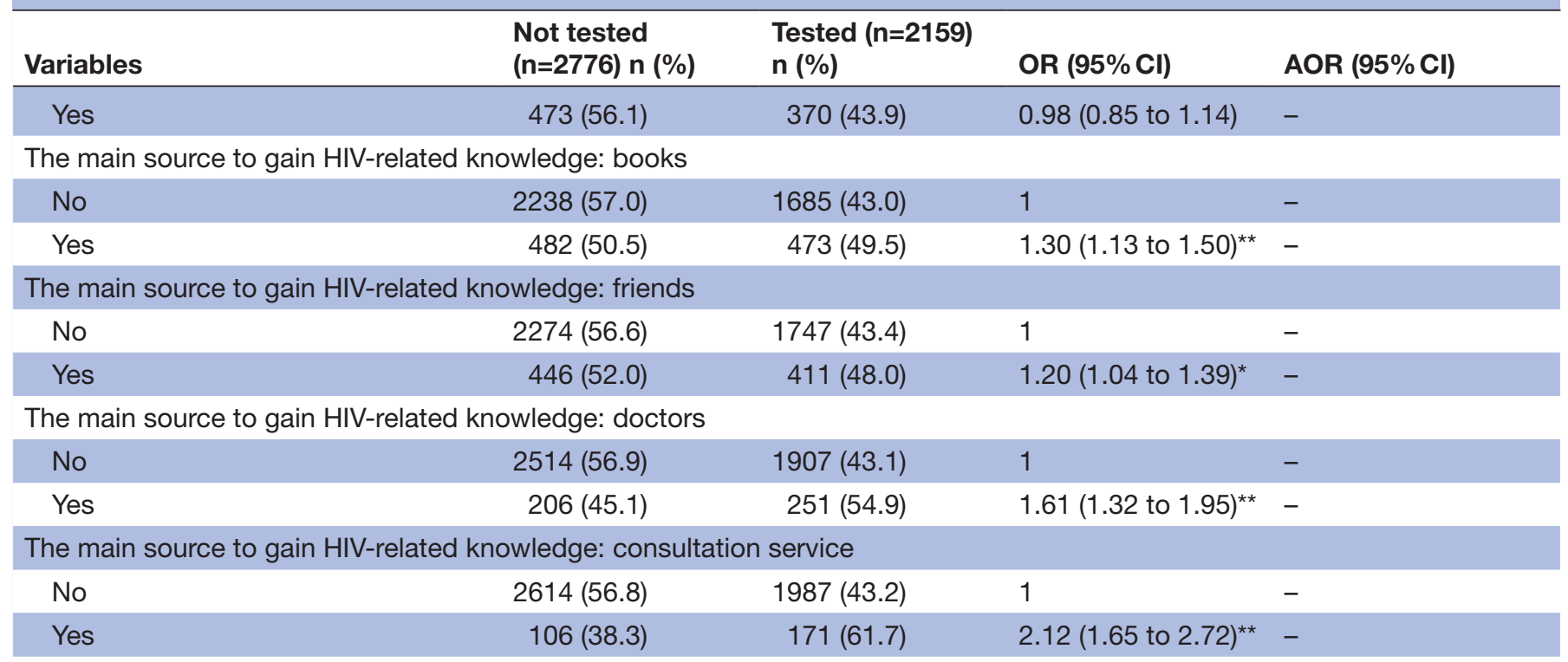

The main source to gain HIV-related knowledge: free promotional materials

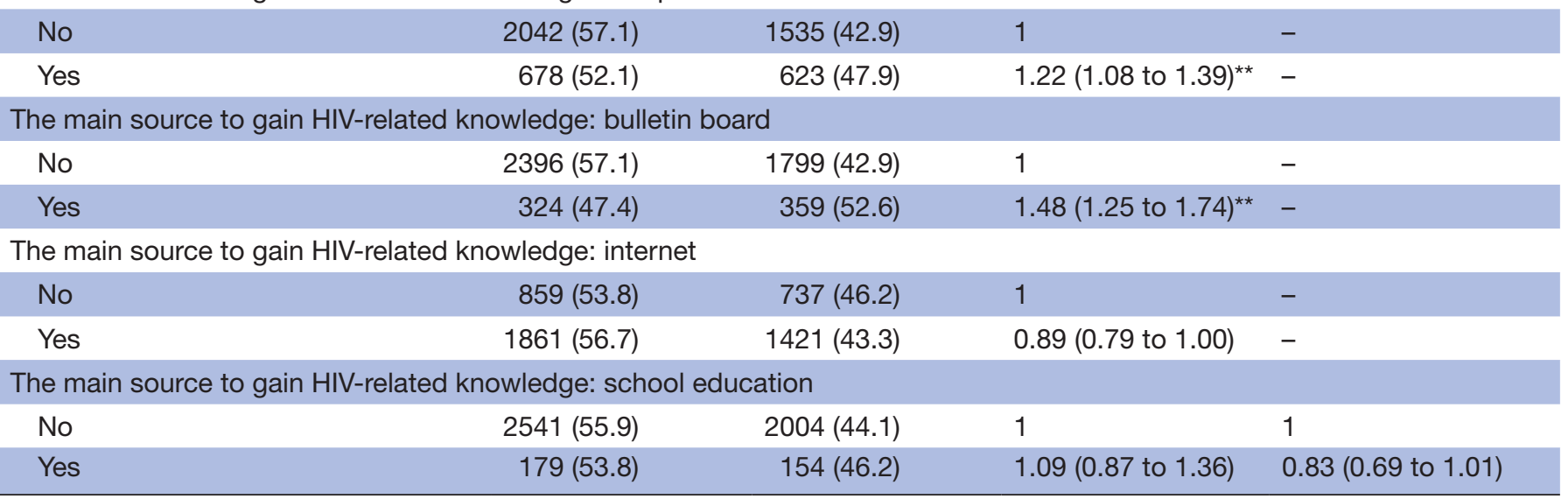

“*”, $p<0.05$; “**”, $p<0.01$; OR, Odds ratio; AOR, adjusted odds ratio; ONS, one night stand; STD, sexually transmitted disease. AOR, adjusted OR; MB, money boy; MSM, men who have sex with men; NcMSM, non-commercial MSM; ONS, one-night stand; STD, sexually transmitted disease.

promotion. ${ }^{15}{ }^{16}$ For instance, Blued, the most popular gay app in China, uses an 'AIDS' ribbon to provide monthly banners on HIV testing, and suggests its users the nearest medical and testing facilities. ${ }^{17}$ Second, as our results found that non-app-using MSM had a relatively lower level of HIV-related knowledge and HIV risk perception, they may be less likely to take an HIV test than app-using MSM.

For the HIV testing approaches preference, both app-using and non-app-using MSM mainly chose to take an HIV test at CDC and CBO, but less often at hospital. The standard public health approaches at public health agencies, such as CDC, are always the mainstay of HIV/ STD services in China. ${ }^{18}$ However, our results showed that compared with the two main approaches, testing in hospitals was less common among both app-using and non-appusing MSM. The literature data also implied the uptake of HIV testing was usually low in a clinical setting. ${ }^{19}$ Owing to the stigma and confidential concerns, Chinese MSM are very wary of taking an HIV test at hospitals. Meanwhile, engagement of $\mathrm{CBO}$ in sexual health prevention may bring about positive social norms to HIV testing and reduce the stigma concerns of MSM. ${ }^{20}{ }^{21}$ Other research showed that the CBO-based testing was a cost-effective approach to reach the population who have low access to clinic-based HIV testing, ${ }^{22}$ and it would be worthwhile for testing expansion and other intervention development and delivery in China. ${ }^{23}$ Therefore, continued efforts of CBOs in promoting HIV testing may further increase the uptake of testing among Chinese MSM.

Testing at gay venues generally was less frequent than the other three main approaches in this study. First, the limited coverage of HIV prevention outreach could explain this finding, as we found only $64 \%$ of the MSM in this study had received the HIV-related service. The current outreach-based HIV services in Shenzhen including HIV testing and counselling, free distribution of condoms and lubricants and STD diagnosis and 
treatment were provided by the local public health agencies (CDC) with limited resources (budget and HIV care professionals) ${ }^{24}$ Second, the literature has documented that MSM were less willing to choose venue-based rapid testing than CBO-based testing among those non-clinical testing sites because of the concerns about quality, cleanliness and professionalism. ${ }^{10}$ Recent studies have also suggested that testing at gay venues, such as saunas and gay bars, was not acceptable among Chinese MSM, unless the test is guaranteed with confidentiality, quality and quick results. ${ }^{25}$ Although app-using MSM showed higher testing rates for the three main testing approaches than non-app-using MSM, they were less likely to get tested at gay venues. As non-app-using MSM more often patronise gay venues to seek sexual partner than app-using MSM do, they were more likely to receive the offline-based HIV-related service $(69.6 \%$ vs $30.4 \%)$ that is routinely delivered at gay venues (eg, bars, massage centres and saunas). This finding indicates that app-using MSM currently are not well reached by traditional HIV prevention and intervention programmes. Thus, innovative intervention strategies are greatly needed for this subpopulation. Besides, future improvements regarding concerns about venue-based rapid testing and increasing HIV-related resource are warranted to remove the barrier to higher uptake of HIV test at gay venues.

The rate of self-testing was much lower than that of other main testing approaches. Although self-testing kits have been widely accessible in China since its distribution was approved in 2008, only $6.1 \%-26.2 \%$ of MSM have ever chosen this new approach. ${ }^{13} 2728$ Compared with non-appusing MSM, app-using MSM showed a higher self-testing rate. A prior study found that the most common means of obtaining self-testing kit in China was the internet, followed by CBOs, pharmacies and other offline means. ${ }^{13}$ Interestingly, there was an increasing trend in selftesting among non-app-using MSM in our study period. The underlying reason may be the scaling up campaign of self-testing in recent years in China, which increases the accessibility of self-testing kit among offline social networking MSM. ${ }^{29}$ Self-testing provides an anonymous and confidential way of HIV testing for MSM, and could better reach high-risk MSM. Our findings demonstrate that there is a large capacity to reach untested MSM via self-testing, especially for those non-app-using MSM who are hard to reach. Therefore, promotion of self-testing would be an alternative approach to increase the HIV testing coverage among Chinese MSM.

Our study found that MSM who were self-identified as homosexual had higher education level, recruited through clinic-based methods, practised receptive sexual role during anal sex, engaged in group sex, used any gay app and had previous diagnosis of other STD with higher odds of HIV testing in the past year. Additionally, older age, multiple sexual partners and previous diagnosis of other STD were associated with higher chance of lifetime HIV testing. These findings were aligned with the literature that associated age, education level, history of other
STD, sexual orientation and high-risk sexual behaviours (eg, multiple male sexual partners and unprotected sexual intercourse) with HIV testing. ${ }^{30}{ }^{31}$ Other studies found that app use, HIV negative serostatus and recent unprotected anal intercourse were positively associated with HIV testing within lifetime and the past year. ${ }^{715}$ Our study also found some other factors, such as access to offline-based HIV-related service in the past year, having a high level of HIV-related knowledge and high HIV risk perception, were significantly associated with HIV testing within the past year, which is consistent with another Chinese study. ${ }^{14}$ These findings highlighted the need for strengthened public health efforts in HIV prevention and interventions to increase the uptake of HIV testing among MSM.

There are several limitations to this study which need to be noted. First, relatively fewer samples were collected in 2016 than in the other 2years; therefore, we have adjusted the confounding effect of sampling year in the multivariate analysis. Second, this study included eight types of gay apps; some new gay apps may emerge in the study period. As Blued accounted for about $97 \%$ of all apps used in this study, newly emerged apps may have limited impact on the results. Third, as this is a cross-sectional study, we are unable to establish a causal relationship; future longitudinal study would be desirable to evaluate the change of testing behaviour over time. In addition, there might be recall bias and socially desirable bias regarding self-reported information, especially sensitive personal behaviours. Lastly, our results may not be generalised to MSM in other areas, caution is required for appropriate interpretation.

In conclusion, there is still a significant gap in the coverage of HIV testing among MSM in Shenzhen, China. It is imperative to expand HIV testing coverage among key population for scale-up treatment, especially among the non-app-using MSM. Smartphone-based gay apps may have considerable potential for increasing HIV testing uptake among the MSM who are otherwise not reachable by traditional outreach. Continued efforts in promoting HIV testing, increased resources of HIV services and innovative strategies are highly needed to achieve the first ' 90 ' target by 2020 .

Acknowledgements We thank all the participants, MSM volunteers and peer researchers, and the staff of the Department of HIV Control and Prevention in Shenzhen Center for Disease Control and Prevention.

Contributors JC and JZ conceived the work. JZ, JC and LL designed the study. LW conducted all data analyses and drafted the manuscript. LC, HZ, SL, WT and WX ran the field investigations, and participated in data collection and management. $\mathrm{LW}, \mathrm{HZ}, \mathrm{ZY}$ and JZ contributed to the writing and data interpretation. WT and WX performed the experiments. LW, LC, ZY, JZ, JC and LL reviewed and edited the manuscript. All authors have seen and approved the final version of the manuscript for publication.

Funding This study was supported by the National Science and Technology Major Project of the Ministry of Science and Technology of China (Grant No 2018ZX10715004), the San-Ming Project of Medicine in Shenzhen (Grant No SZSM201811007) and the Shenzhen Municipal Technological Project (Grant No JCYJ20170306160440762).

Competing interests None declared. 
Patient consent for publication Not required.

Ethics approval The protocol for recruitment was approved by the Medical Ethics Committee of Shenzhen Center for Disease Control and Prevention.

Provenance and peer review Not commissioned; externally peer reviewed.

Data availability statement All data relevant to the study are included in the article or uploaded as supplementary information.

Open access This is an open access article distributed in accordance with the Creative Commons Attribution Non Commercial (CC BY-NC 4.0) license, which permits others to distribute, remix, adapt, build upon this work non-commercially, and license their derivative works on different terms, provided the original work is properly cited, appropriate credit is given, any changes made indicated, and the use is non-commercial. See: http://creativecommons.org/licenses/by-nc/4.0/.

\section{REFERENCES}

1. Marks G, Crepaz N, Janssen RS. Estimating sexual transmission of HIV from persons aware and unaware that they are infected with the virus in the USA. AIDS 2006;20:1447-50.

2. HIV testing and counselling: World Health Organization. Available: http://www.who.int/hiv/topics/vct/about/en/index.html [Accessed 18 Nov 2018].

3. Zou H, Hu N, Xin Q, et al. Hiv testing among men who have sex with men in China: a systematic review and meta-analysis. AIDS Behav 2012;16:1717-28.

4. Wei C, Yan H, Yang C, et al. Accessing HIV testing and treatment among men who have sex with men in China: a qualitative study. AIDS Care 2014;26:372-8.

5. Zou H, Fan S. Characteristics of men who have sex with men who use smartphone Geosocial networking applications and implications for HIV interventions: a systematic review and meta-analysis. Arch Sex Behav 2017;46:885-94.

6. Phillips G, Magnus M, Kuo I, et al. Use of geosocial networking (GSN) mobile phone applications to find men for sex by men who have sex with men (MSM) in Washington, DC. AIDS Behav 2014;18:1630-7.

7. Bien $\mathrm{CH}$, Best JM, Muessig KE, et al. Gay Apps for seeking sex partners in China: implications for MSM sexual health. AIDS Behav 2015;19:941-6.

8. Lehmiller JJ, loerger M. Social networking smartphone applications and sexual health outcomes among men who have sex with men. PLoS One 2014;9:e86603.

9. Cao B, Liu C, Durvasula M, et al. Social media engagement and HIV testing among men who have sex with men in China: a nationwide cross-sectional survey. J Med Internet Res 2017;19:e251.

10. Bien $\mathrm{CH}$, Muessig KE, Lee R, et al. HIV and syphilis testing preferences among men who have sex with men in South China: a qualitative analysis to inform sexual health services. PLoS One 2015;10:e0124161.

11. Zhao J, Cai R, Chen L, et al. A comparison between respondentdriven sampling and time-location sampling among men who have sex with men in Shenzhen, China. Arch Sex Behav 2015;44:2055-65.

12. Zhao J, Cai W-D, Gan Y-X, et al. A comparison of HIV infection and related risk factors between money boys and noncommercial men who have sex with men in Shenzhen, China. Sex Transm Dis 2012;39:942-8.

13. Han L, Bien $\mathrm{CH}$, Wei $\mathrm{C}$, et al. HIV self-testing among online MSM in China: implications for expanding HIV testing among key populations. J Acquir Immune Defic Syndr 2014;67:216-21.

14. Li R, Pan X, Ma Q, et al. Prevalence of prior HIV testing and associated factors among MSM in Zhejiang Province, China: a crosssectional study. BMC Public Health 2016;16:1152.

15. Rendina HJ, Jimenez RH, Grov C, et al. Patterns of lifetime and recent HIV testing among men who have sex with men in New York City who use Grindr. AIDS Behav 2014;18:41-9.

16. Kirby T, Thornber-Dunwell M. Phone apps could help promote sexual health in MSM. Lancet 2014;384.

17. Taking China's Fight Against AIDS. Available: https://thediplomat. com/2016/01/taking-chinas-fight-against-aids-online/ [Accessed 10 Sep 2018].

18. Tucker JD, Fenton KA, Peckham R, et al. Social entrepreneurship for sexual health (SESH): a new approach for enabling delivery of sexual health services among most-at-risk populations. PLoS Med 2012;9:e1001266.

19. Chirawu P, Langhaug L, Mavhu W, et al. Acceptability and challenges of implementing voluntary counselling and testing (VCT) in rural Zimbabwe: evidence from the Regai Dzive Shiri project. AIDS Care 2010;22:81-8.

20. Ramirez-Valles J. The protective effects of community involvement for HIV risk behavior: a conceptual framework. Health Educ Res 2002;17:389-403.

21. Latkin C, Weeks MR, Glasman L, et al. A dynamic social systems model for considering structural factors in HIV prevention and detection. AIDS Behav 2010;14(S2):222-38.

22. Suthar $A B$, Ford N, Bachanas PJ, et al. Towards universal voluntary HIV testing and counselling: a systematic review and meta-analysis of community-based approaches. PLoS Med 2013;10:e1001496.

23. Zhang TP, Liu C, Han L, et al. Community engagement in sexual health and uptake of HIV testing and syphilis testing among MSM in China: a cross-sectional online survey. J Int AIDS Soc 2017;20:21372.

24. Zhao J, Cai W-D, Chen L, et al. A comparison of HIV infection and related risks among male sex workers in different venues in Shenzhen, China. AIDS Behav 2011;15:635-42.

25. Han L, Wei C, Muessig KE, et al. HIV test uptake among MSM in China: implications for enhanced HIV test promotion campaigns among key populations. Glob Public Health 2017;12:31-44.

26. Tucker JD, Bien $\mathrm{CH}$, Peeling RW. Point-Of-Care testing for sexually transmitted infections: recent advances and implications for disease control. Curr Opin Infect Dis 2013;26:73-9.

27. Yan H, Yang H, Raymond HF, et al. Experiences and correlates of HIV self-testing among men who have sex with men in Jiangsu Province, China. AIDS Behav 2015;19:485-91.

28. Wong HTH, Tam HY, Chan DPC, et al. Usage and acceptability of HIV Self-testing in men who have sex with men in Hong Kong. AIDS Behav 2015;19:505-15.

29. Tucker JD, Ong J, Conserve D, et al. Scaling up HIV self-testing in China and Africa. J Virus Erad 2017;3.

30. Wei C, Ruan S, Zhao J, et al. Which Chinese men who have sex with men miss out on HIV testing? Sex Transm Infect 2011;87:225-8.

31. Song Y, Li X, Zhang L, et al. Hiv-Testing behavior among young migrant men who have sex with men (MSM) in Beijing, China. AIDS Care 2011;23:179-86. 
Correction: Relationship between gay app use and HIV

testing among men who have sex with men in Shenzhen, China: a serial cross-sectional study

Wei L, Chen L, Zhang H, et al. Relationship between gay app use and HIV testing among men who have sex with men in Shenzhen, China: a serial cross-sectional study. BMJ Open 2019;9:e028933. doi: 10.1136/bmjopen-2019-028933

The previous version of this manuscript left out to include co-corresponding author.

Dr. Jin Zhao; zhaoj@szcdc.net

Open access This is an open access article distributed in accordance with the Creative Commons Attribution Non Commercial (CC BY-NC 4.0) license, which permits others to distribute, remix, adapt, build upon this work non-commercially, and license their derivative works on different terms, provided the original work is properly cited, appropriate credit is given, any changes made indicated, and the use is non-commercial. See: http://creativecommons.org/licenses/by-nc/4.0/.

(c) Author(s) (or their employer(s)) 2019. Re-use permitted under CC BY-NC. No commercial re-use. See rights and permissions. Published by BMJ.

BMJ Open 2019;9:e028933corr1. doi:10.1136/bmjopen-2019-028933corr1

A) Check for updates 